\title{
The roles of cell wall invertase inhibitor in regulating chilling tolerance in tomato
}

\author{
Xiao-xia Xu, Qin Hu, Wan-nian Yang and Ye Jin*
}

\begin{abstract}
Background: Hexoses are important metabolic signals that respond to abiotic and biotic stresses. Cold stress adversely affects plant growth and development, limiting productivity. The mechanism by which sugars regulate plant cold tolerance remains elusive.

Results: We examined the function of INVINH1, a cell wall invertase inhibitor, in tomato chilling tolerance. Cold stress suppressed the transcription of INVINH1 and increased that of cell wall invertase genes, Lin6 and Lin8 in tomato seedlings. Silencing INVINH1 expression in tomato increased cell wall invertase activity and enhanced chilling tolerance. Conversely, transgenic tomatoes over-expressing INVINH1 showed reduced cell wall invertase activity and were more sensitive to cold stress. Chilling stress increased glucose and fructose levels, and the hexoses content increased or decreased by silencing or overexpression INVINH1. Glucose applied in vitro masked the differences in chilling tolerance of tomato caused by the different expressions of INVINH1. The repression of INVINH1 or glucose applied in vitro regulated the expression of C-repeat binding factors (CBFs) genes. Transcript levels of NCED1, which encodes 9-cisepoxycarotenoid dioxygenase (NCED), a key enzyme in the biosynthesis of abscisic acid, were suppressed by INVINH1 after exposure to chilling stress. Meanwhile, application of ABA protected plant from chilling damage caused by the different expression of INVINH1.
\end{abstract}

Conclusions: In tomato, INVINH1 plays an important role in chilling tolerance by adjusting the content of glucose and expression of CBFs.

Keywords: Abscisic acid, Cell wall invertase inhibitor, Chilling tolerance, C-repeat binding factors, Solanum lycopersicum, Sugar signaling

\section{Background}

In higher plants, sucrose is the major transport form of carbohydrates. Cleavage of sucrose is catalyzed by either sucrose synthase (EC 2.4.1.13) or invertase (EC 3.2.1.26). The products (hexoses) are not only substrates of respiration and biosynthesis, but also important metabolic signals in plant response to abiotic and biotic stresses [1-5].

Invertases irreversibly hydrolyze sucrose into glucose and fructose. Based on their $\mathrm{pH}$ optima, solubility characteristics and subcellular localization, invertases are categorized as vacuolar, neutral/alkaline and cell wall invertases [6-9]. Both vacuolar and neutral/alkaline invertases are soluble, with an acidic pI, while cell wall invertases are insoluble, with a mostly basic pI. Unlike

\footnotetext{
* Correspondence: jinye@mail.ccnu.edu.cn

Hubei Key Laboratory of Genetic Regulation and Integrative Biology, School of Life Sciences, Central China Normal University, Wuhan 430079, People's Republic of China
}

(c) The Author(s). 2017 Open Access This article is distributed under the terms of the Creative Commons Attribution 4.0 International License (http://creativecommons.org/licenses/by/4.0/), which permits unrestricted use, distribution, and reproduction in any medium, provided you give appropriate credit to the original author(s) and the source, provide a link to the Creative Commons license, and indicate if changes were made. The Creative Commons Public Domain Dedication waiver (http://creativecommons.org/publicdomain/zero/1.0/) applies to the data made available in this article, unless otherwise stated.

the enzymes in vacuoles or cell walls, neutral/alkaline invertases are not glycosylated and possess an optimal $\mathrm{pH}$ of 7.0-7.8 [8,9]. Neutral/alkaline invertases, localized in cytoplasm and mitochondria [10], are essential for normal plant growth, development and stress responses. Vacuolar invertases, with an optimal $\mathrm{pH}$ of 4.7-5.5, correlate with the sugar accumulation in sink tissues [11, $12]$ and cell expansion [13, 14]. Cell wall invertases, with an optimal $\mathrm{pH}$ of 4.3-5.5, hydrolyze sucrose to maintain the sucrose concentration gradient between source and sink tissues [15]. Much progress has been made in understanding the role of cell wall invertase in sink tissue (seed \& fruit) development [16-20], in fruit-set under heat stress [21] or during water deficit [6], and in leaf senescence [22].

The protein of cell wall invertase is intrinsically stable because of their glycosylated nature $[6,23]$. Thus, the activity of cell wall invertase is largely regulated at the 
protein level. Inhibitors directly target the invertase active site and compete with sucrose, the substrate of invertase, for the same binding site [24]. After the initial biochemical characterization [25], a group of small proteins $(<20 \mathrm{KD})$ were observed to inhibit the activity of invertase in tobacco [26], maize [27], tomato [18, 28], potato [29], soybean [30] and Arabidopsis [31].

Transgenic approaches have led to some progress in understanding the role of invertase inhibitors in plants. Overexpression of an invertase inhibitor in potato prevented cold-induced sweetening of potato tubers [12, 32, 33]. Suppressing the expression of cell wall invertase inhibitor led to an increase of seed weight in soybean [30] and seed germination in Arabidopsis [31]. Jin et al. [18] demonstrated that INVINH1 (a cell wall invertase inhibitor) could regulate the activity of the cell wall invertase in vivo, and silencing the expression of INVINH1 in tomato resulted in enlarged seed size, increased sugar content in fruit and delayed leaf senescence. These studies focused on the function of INVINH1 in sink tissues rather than in vegetative organs, although INVINH1 was highly expressed in root, stem and leaf during the vegetative period.

Interestingly, the expression of the cell wall invertase inhibitor was induced by abscisic acid [18, 23, 30], which is involved in the response to various biotic and abiotic stresses, including chilling stress [34]. Low temperature is an important factor which affects the growth and development of plants. Plants adjust the delicate balance between multiple pathways, including transcription factor, DNA modification, hormones, secondary messengers, phosphatases and protein kinases among others to get acclimatized [35]. The content of sugar, known to have an osmoprotective function increased during cold treatment [36]. Glucose induced the expression of cold response genes [37]. The ectopic expression of tomato GDP-L galactose phosphorylase gene in tobacco enhanced tolerance to chilling stress [38]. These above suggested that sucrose metabolism may be involved in the regulation of chilling tolerance. However little was known about the function of cell wall invertase activity in chilling stress tolerance. This study aimed to explore the roles of INVINH1 in tomato cold tolerance and our data highlight the function of INVINH1 in plant tolerance to cold stress and provide a possible mechanism of plant cold tolerance.

\section{Methods}

\section{Plant material, growth conditions and cold treatments}

Tomatoes (Solanum lycopersicum XF-2) were grown in the greenhouse with $16 \mathrm{~h}$ of light at $25-27^{\circ} \mathrm{C}$ and $8 \mathrm{~h}$ of darkness at $22^{\circ} \mathrm{C}$. Under this conditions the visible flower buds appear 65-75 days after germinate, so we chose 45 days old and 60 days old plants in this study.
The first mature leaf was used for RT-PCR, proline content and the peroxidase (POD) activities measurement. For plants grown in vitro, seeds were surface sterilized and germinated on half-strength MS medium without sugar at $25^{\circ} \mathrm{C}$ with a 16 -h photoperiod. For cold treatments, plants were transferred from $25^{\circ} \mathrm{C}$ to $4{ }^{\circ} \mathrm{C}$ and were maintained under the same photoperiod as previously described.

\section{Gene constructs and plant transformation}

To construct Rbcs3a:INVINH1, the full-length Rbsc3a promoter [39] was digested with XbaI and HindIII and cloned into vector pCAMBIA1300 (Cambia), upstream of INVINH1.

Tomato plants were transformed with Rbcs3a:INVINH1 constructs according to Jin et al. [18]. PCR analysis was used to monitor the incorporation of the transgene. Plants transformed with Rbcs3a:INVINH1 were analyzed using the following primer pair:5'-GC CTCTAGATATTGCTTTCTAGTCTCT-3' and 5'-GAA TTCCAATAAATTTCTTACAAT-3'. Twenty-four primary transgene $\left(\mathrm{T}_{0}\right)$ lines were generated. Among them, three were PCR-positive for the transgene.

\section{Semi-quantitative and real-time RT-PCR analysis}

Leaves were collected, immediately frozen in liquid $\mathrm{N}_{2}$ and stored at $-80^{\circ} \mathrm{C}$. A total RNA kit (Invitrogen) was used to isolate total RNA from the stored leaves, which was then treated with RNase-free DNase (Promega) to remove genomic DNA. M-MLV reverse transcriptase (Takara) was used to synthesize first-strand cDNA. A tomato ACTIN fragment amplified with Actin-RT primers was used as an internal control. The primer sequences are listed in Additional file 1: Table S1.

\section{POD activity assays}

Leaves $(0.3 \mathrm{~g})$, which were harvested from plants after cold treatment, were ground with $9 \mathrm{ml}$ of ice-cold $20 \mathrm{mM} \mathrm{KH_{2 }} \mathrm{PO}_{4}$ buffer. The homogenates were centrifuged at $4000 \mathrm{~g}$ at $4^{\circ} \mathrm{C}$ for $15 \mathrm{~min}$ and supernatants were used to determine enzymatic activity. POD activity was assayed by measuring the increase in absorbance at $470 \mathrm{~nm}$ for $3 \mathrm{~min}$. The assay mixture ( $3 \mathrm{ml}$ final volume) comprised $100 \mathrm{mM}$ potassium phosphate buffer (pH 6.0), $3.7 \mathrm{mM} \mathrm{H}_{2} \mathrm{O}_{2}, 5.0 \mathrm{mM}$ guaiacol and $1 \mathrm{ml}$ enzyme extract [40]. POD activity $1 \mathrm{U}$ means "the change of $\mathrm{OD}_{470 \mathrm{~nm}}$ per minute per gram fresh weight". Each value is mean $\pm \mathrm{SE}$ of at least ten biological replicates.

\section{Proline content measurement}

Proline contents were determined according to [41], with some modifications. Leaves (approximately $0.3 \mathrm{~g}$ )

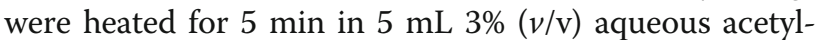
salicylic acid. After cooling, the homogenate was filtered. 
The filtrate was mixed with glacial acetic acid, deionized water $(2 \mathrm{ml}$ each) and acid-ninhydrin agent $(4 \mathrm{~mL})$ and heated for $1 \mathrm{~h}$ at $100^{\circ} \mathrm{C}$. The reaction mixture was extracted with $4 \mathrm{~mL}$ toluene. Absorbance at $520 \mathrm{~nm}$ was used to calculate the proline content. $1 \mu \mathrm{g} / \mathrm{mL}, 2.5 \mu \mathrm{g} /$ $\mathrm{mL}, 5 \mu \mathrm{g} / \mathrm{mL}, 10 \mu \mathrm{g} / \mathrm{mL}, 15 \mu \mathrm{g} / \mathrm{mL}, 20 \mu \mathrm{g} / \mathrm{mL}$ purified proline were used as standards to produce calibration curve. Each value is mean \pm SE of at least ten biological replicates.

\section{Enzyme assay and sugar measurement}

Cell wall, vacuolar, and cytoplasmic invertase activities and sugar levels were assayed as described by Jin et al. [18]. Each value is mean \pm SE of at least three biological replicates.

\section{ABA content measurement}

An Abscisic acid immunoassay detection kit (Sigma PGR1) was used to quantitate the levels of ABA in tomato. Each value is mean $\pm \mathrm{SE}$ of at least four biological replicates.

\section{Results}

Cell wall invertase activity correlates with tomato cold tolerance

Previous research cloned the tomato cell wall invertase inhibitor (INVINH1, accession number: AJ010943) and showed that the expression of INVINH1 was induced by ABA [18], an abiotic stress-related hormone. To determine the function of cell wall invertase and its inhibitor during tomato chilling tolerance, we compared invertase gene expression and activity of $10-\mathrm{d}$ tomato seedlings before and after cold stress. The expressions of the only two known cell wall invertase genes (Lin6 and Lin8) in tomato seedling were induced after treatment at $4^{\circ} \mathrm{C}$ for $2 \mathrm{~h}$; by contrast, the expression of the cell wall invertase inhibitor gene (INVINH1) was depressed (Fig. 1a). Enzyme assays revealed that, compared with untreated plants, apoplastic invertase activity increased by about $150 \%$ after treatment at $4^{\circ} \mathrm{C}$ for $2 \mathrm{~h}$ and by about $520 \%$ after treatment for $24 \mathrm{~h}$ (Fig. 1b). These results suggest that cell wall invertase might be involved in chilling tolerance of tomato.

\section{Silencing INVINH 1 in tomato enhances chilling tolerance} In our earlier experiment, we silenced the expression of INVINH1 in tomato by transforming an RNA interference (RNAi) construct and obtained three $\mathrm{T}_{2}$ homozygous transgenic lines [18]. To determine the roles of the cell wall invertase inhibitor during tomato cold tolerance, 45-day-old and 60-day-old INVINH1 RNAi plants were treated at $4^{\circ} \mathrm{C}$ independently. After treated at $4^{\circ} \mathrm{C}$ for $10 \mathrm{~h}$, the top leaves of 45-day-old wildtype plants were already wilting, but the counterpart of RNAi plants were not obviously affected

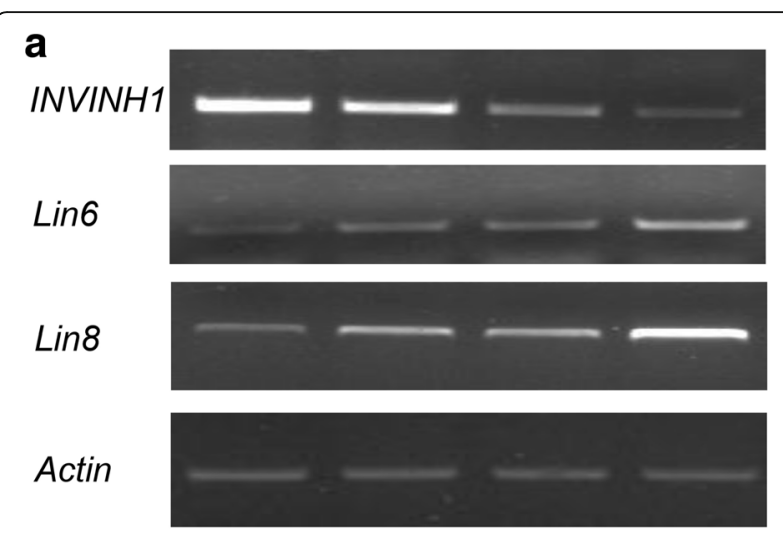

b

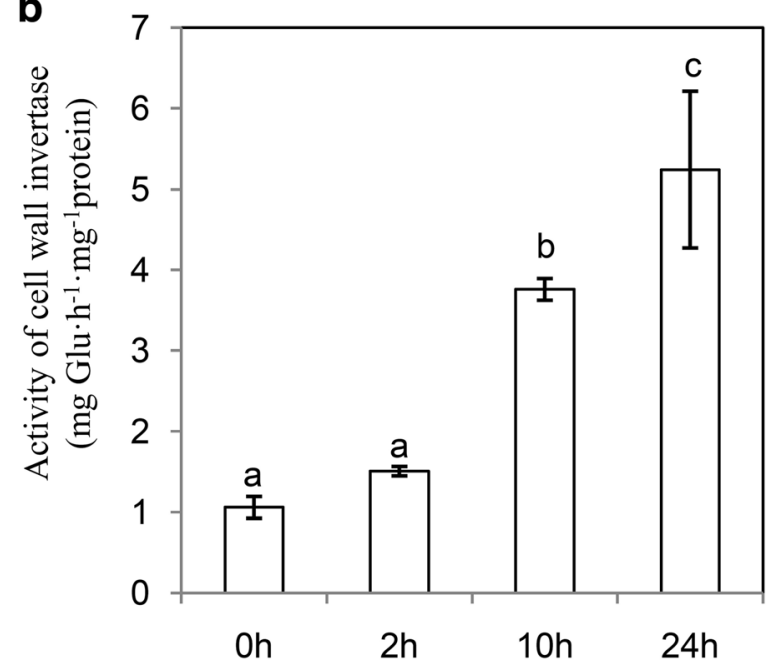

Fig. 1 Cold suppressed INVINH1 expression, induced cell wall invertase gene expression, meanwhile increased the activity of cell wall invertase in tomato seedlings. a RT-PCR analysis the expression of cell wall invertase gene (Lin6 and Lin8) and cell wall invertase inhibitor gene (INVINH1). Expression of actin gene (actin) was used as an internal control. b Activity of cell wall invertases was progressively induced by cold treatment. Each value is mean \pm SE of at least four biological replicates. Lowercase letters indicate values significantly different at $P<0.05$

(Fig. 2a \& b). As for 60-day-old plants, $48 \mathrm{~h}$ of $4^{\circ} \mathrm{C}$ treatments wilted both the RNAi and wildtype plants. However the RNAi plants recovered earlier than the wildtype plants when transferred to $25^{\circ} \mathrm{C}$. As shown in Fig. 2c \& d, h recover at $25^{\circ} \mathrm{C}$ restored the first mature leaf to normal phenotype, while the leaf at the same position in the wildtype plant remained wilted. After recovered at $25^{\circ} \mathrm{C}$ for 5 days, both INVINH1 RNAi and wildtype plants recovered. However, the third mature leaf from the top of 60-day-old wildtype plants was notably injured and the base of the leaf turned white, while the same position of the leaf of the INVINH1 RNAi plant was not obviously affected at this stage (Fig. 2e \& f).

The accumulation of reactive oxygen species (ROS) is one of the major factors leading to chilling injury. Plant cells scavenge excess ROS using complex antioxidant 

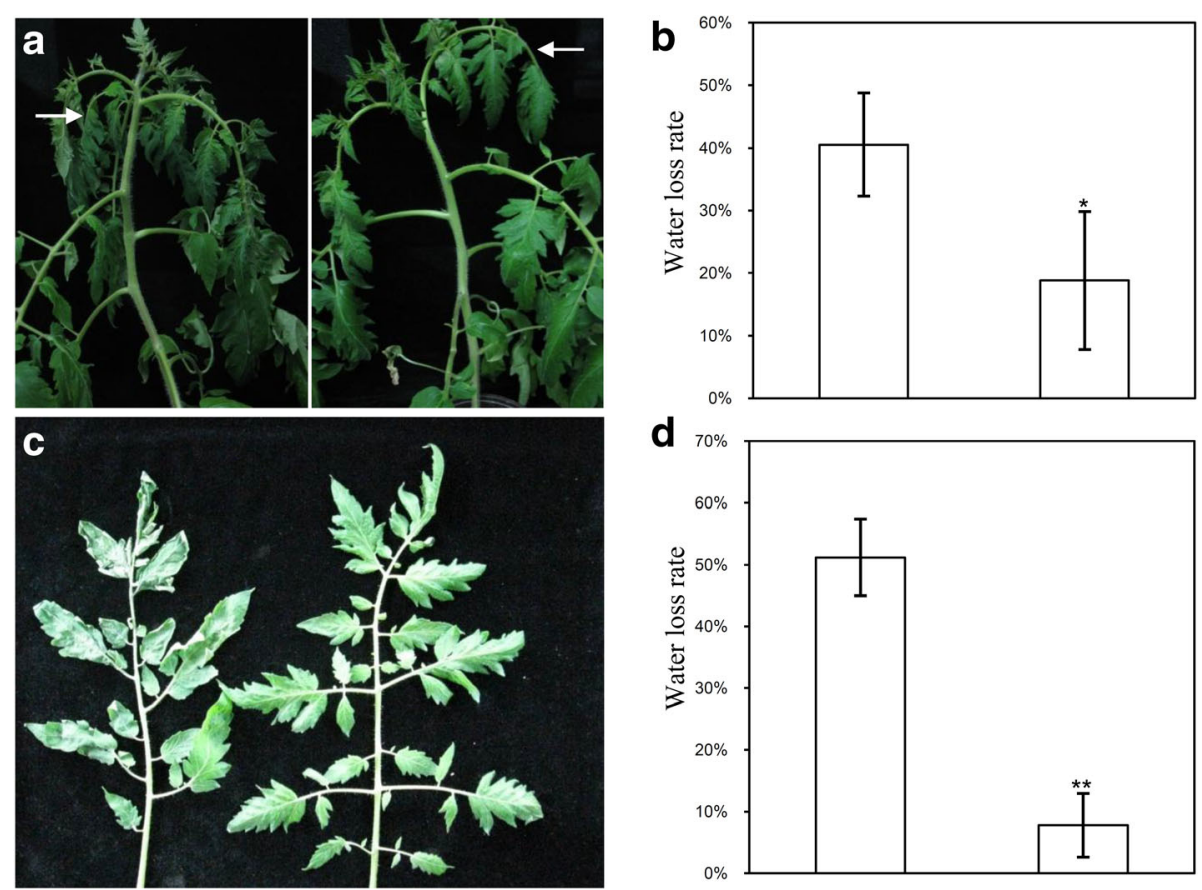

d
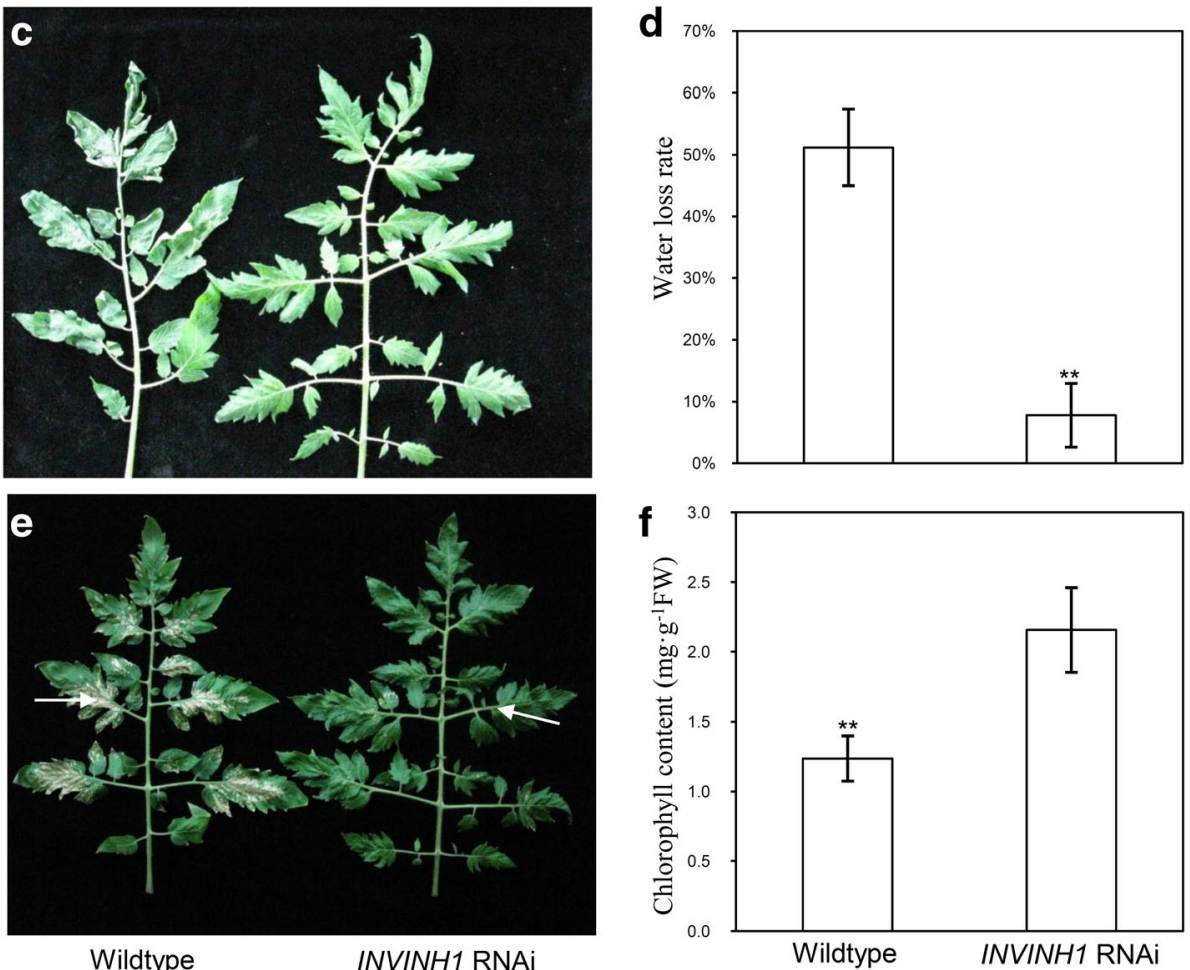

Fig. 2 INVINH1 silencing-expression enhanced chilling tolerance of tomato. a 45-d INVINHI RNAi and wildtype plant were treated at $4{ }^{\circ} \mathrm{C}$ for $10 \mathrm{~h}$. The wildtype plant wilted, while INVINH1 RNAi plant remained normal. $\mathbf{b}$ Water loss rate of the first and second mature leaves from (a). c The first mature leaf from 60-d INVINH1 RNAi and wildtype plant, which were recovered at $25^{\circ} \mathrm{C}$ for $2 \mathrm{~h}$ after treated at $4{ }^{\circ} \mathrm{C}$ for $48 \mathrm{~h}$. The leaf at this position of INVINH1 RNAi plant returned to normal at this time. $\mathbf{d}$ Water loss rate of the leaves from (c). e The third mature leaf from 60-d INVINH1 RNAi and wildtype plant, which were recovered at $25^{\circ} \mathrm{C}$ for $120 \mathrm{~h}$ after treated at $4{ }^{\circ} \mathrm{C}$ for $48 \mathrm{~h}$. The leaf at this position of wildtype plant turned white. By contrast, the leaf at the same position of INVINH1 RNAi remained green at this stage. $\mathbf{f}$ The chlorophyll content of the leaves from (e). Each value in (b), (d) and (f)is mean \pm SE of at least ten biological replicates. An asterisk indicates a significant difference $\left(t\right.$ test, $\left.{ }^{*} P<0.05 ;{ }^{*} P<0.01\right)$

system including peroxidase (POD). Proline is a known protector in abiotic stress and oxidative damage. Hsieh et al. [42] reported that the proline level is elevated in the cold insensitive transgenic tomato overexpressing CBF1. The activation of peroxidase (POD) and proline synthesis was used as biomarkers of chilling stress in tomato [43-45]. So we measured POD activity and proline content. $4^{\circ} \mathrm{C}$ treatment induced proline accumulation and peroxidase (POD) activities in both INVINH1 RNAi and wildtype plants. After $24 \mathrm{~h}$ of cold treatment, the levels of proline and activities of POD were significantly lower in the wildtype than in INVINH1 RNAi plants (Fig. 3a \& b). Compared with untreated leaves, transformation with the INVINH1 RNAi construct increased proline content by an average of $85.5 \%$ and POD activity by $51.2 \%$ after cold treatment. By contrast, wildtype plants increased their proline content by an average of $58.9 \%$ and their POD activity by $42.5 \%$ after cold treatment. These results indicate that wildtype tomato plants are more sensitive to low temperature than INVINH1 RNAi plants. The other two INVINH1 RNAi lines (line 2\&8) showed similar results to line 1 as presented in Additional file 1: Figure S1.

INVINH1 overexpression tomatoes are more sensitive than wildtype plants to chilling stress

To further examine the role of INVINH1 in tomato cold tolerance, we transformed tomato plants with an INVINH1 

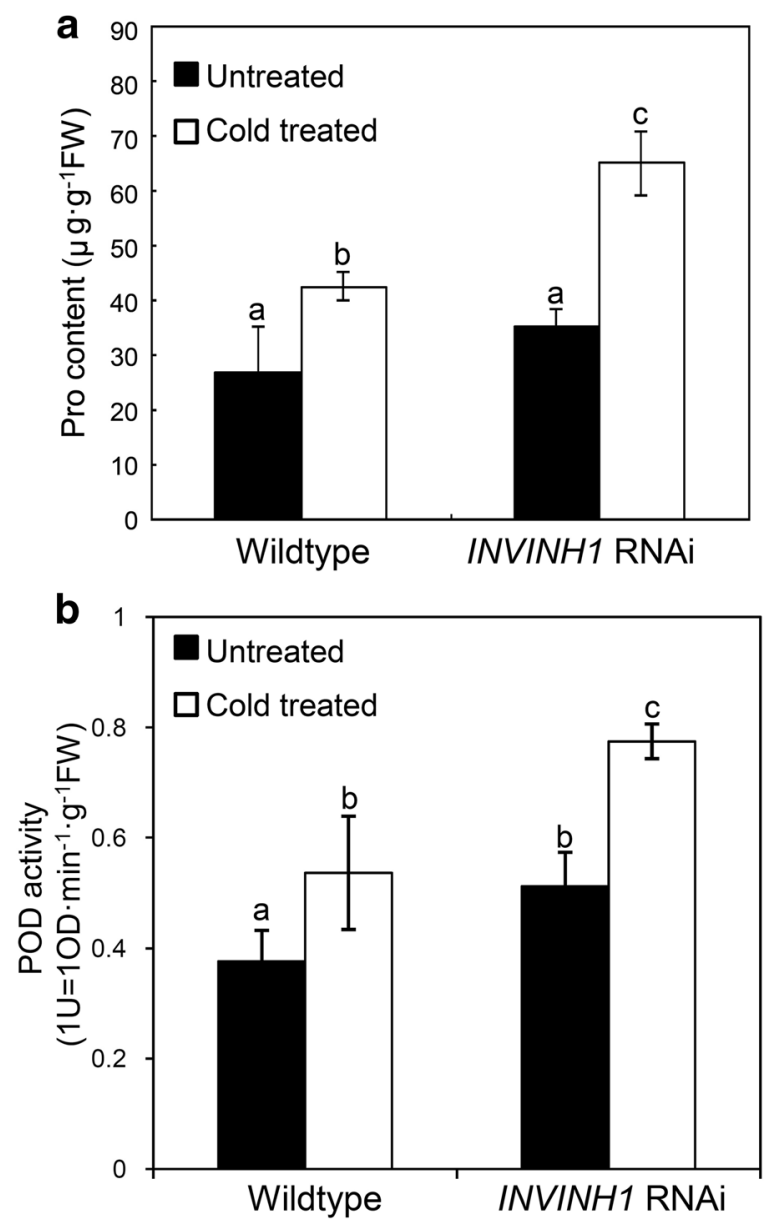

Fig. 3 Proline content and the peroxidase (POD) activities in wildtype and INVINH1-scilencing plants under cold stresses. a The proline content of the first mature leaf from INVINH1 RNAi and wildtype plant before and after treated at $4{ }^{\circ} \mathrm{C}$ for $24 \mathrm{~h}$. $\mathbf{b}$ The POD activity of the first mature leaf from INVINH1 RNAi and wildtype plant before and after treated at $4{ }^{\circ} \mathrm{C}$ for $24 \mathrm{~h}$. (POD activity: $1 \mathrm{U}=\mathrm{OD} \cdot \mathrm{min}^{-1} \cdot \mathrm{g}^{-1} \mathrm{FW}$ ). Each value in (a) is mean \pm SE of ten biological replicates. Each value in $(\mathbf{b})$ is mean \pm SE of fifteen biological replicates. Lowercase letters indicate values significantly different at $P<0.05$

overexpression construct. In our earlier experiment, we introduced a 35S:INVINH1 overexpression construct into tomato. Unfortunately, all transgenic seeds aborted and no $\mathrm{T} 1$ progeny were obtained [18]. To solve this problem, the Rbsc3A promoter, which does not have transcriptional activity in tomato seeds [39], was used to replace the 35S promoter in the overexpression construct. The Rbsc3A:INVINH1 overexpression construct was introduced into tomato through Agrobacterium tumefaciens-mediated transformation. Three primary transgenic lines (T0) were identified. The T0 plants were self-pollinated for seeds. T1 generations were analyzed to identify the presence or absence of the transgene by PCR [46]. Three T1 lines were used for detailed analysis along with their non-transgenic segregants, which were analogous to the wildtype.
RT-PCR analyses showed that the transcription of INVINH1 was significantly increased in the three transgenic lines, compared with the wild-type (Fig. 4a). Notably, among the three lines, line 2 showed the maximum level of INVINH1 transcription (Fig. 4a). The overexpression of INVINH1 led to a significant decrease in cell wall invertase activity in line $2 \& 21$. Especially in line 2 the transcription increase of INVINH1 led to $42 \%$ decrease in cell wall invertase activity (Fig. 4b). Thus this was used for further analysis. No alteration of cytoplasmic or vacuolar invertases activities between transgenic and wild-type plants were detected in transgenic lines (Fig. 4b).

We exposed 45-day-old INVINH1 overexpression and wildtype plants to $4^{\circ} \mathrm{C}$. Figure $5 \mathrm{a}$ shows that the INVINH1 overexpression plant was injured after exposure to $4^{\circ} \mathrm{C}$ for $6 \mathrm{~h}$, but the wildtype was not obviously affected. Both 60-day-old INVINH1 overexpression and wildtype plants recovered when revived at $25^{\circ} \mathrm{C}$ for 3 days after cold treatment. However, the first mature
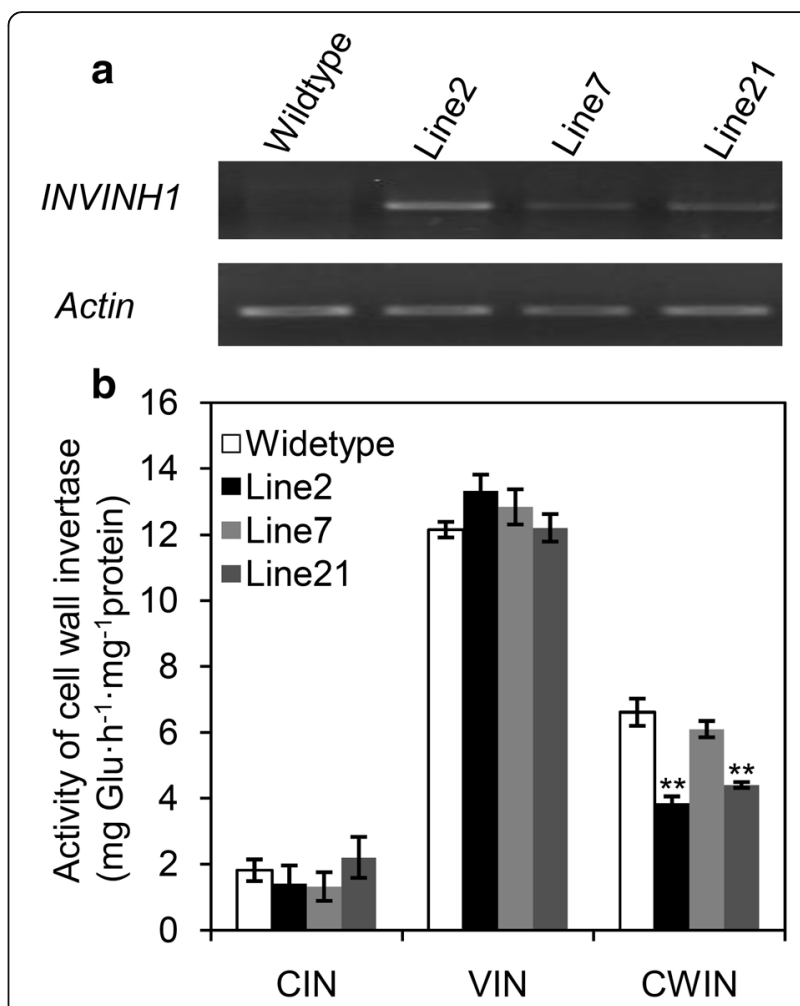

Fig. 4 Over-expression INVINH1 in tomato significantly depressed cell wall invertase activity. a RT-PCR analysis revealed INVINHI expression was increased in the mature leaves of INVINH1 over-expression plants. The actin gene was used as an internal control. b Cell wall invertase (CWIN) activity of transgenic line2 \& 21 was reduced significantly in the mature leaves in comparison with wildtype plant ( $t$ test $p<0.01$ ). While the activity of cytoplasmic (CIN) and vacuolar invertases (VIN) were not affected. Each value in (b) is mean \pm SE of at least three biological replicates. An asterisk indicates a significant difference $\left(t\right.$ test, $\left.{ }^{* *} \mathrm{P}<0.01\right)$ 
leaf from the top of the INVINH1 overexpression plant was notably injured and the base of the leaf turned white, while the same position on the leaf of the wildtype plant was not obviously affected at this stage (Fig. $5 \mathrm{~b})$. The phenotypic responses of INVINH1 over-expression line 21 were similar to line 2 (Additional file 1: Figure S2).

Consistent with the previous results for INVINH1 RNAi plants, $4^{\circ} \mathrm{C}$ treatment induced proline accumulation and peroxidase (POD) activities in both INVINH1 overexpression and wildtype plants. After $24 \mathrm{~h}$ of cold treatment, the levels of proline and activities of POD were significantly higher in wildtype compared with the INVINH1 overexpression plants (Fig. $5 c$ \& d). In comparison with untreated leaves, transforming with INVINH1 overexpression construct increased the proline content by an average of $57.7 \%$ and POD activity by $13.7 \%$. In contrast, the wildtype plant increased its proline content by an average of $61.7 \%$ and its POD activity by $42.8 \%$. These results indicated that INVINH1 overexpression plants are more sensitive than wildtype plants to low temperature.

\section{Regulation of Lin6 \& INVINH1 gene expression and sugar content in INVINH1 overexpression and silenced plants under chilling stress}

To explore the mechanism of how INVINH1 regulates cold tolerance in tomatoes, the expressions of the cell wall invertase gene Lin6 and INVINH1 were analyzed using real-time RT-PCR. The results revealed that the expression of INVINH1 was depressed by cold treatment in both INVINH1 overexpression and wildtype plants. The INVINH1 transcript was barely detected in INVINH1 silenced plants (Fig. 6a). The mRNA level of cell wall invertase Lin6 was not affected by silencing or overexpression of the invertase inhibitor. Cold treatment increased the transcript levels of Lin6 in both transgenic (INVINH1 overexpression and RNAi) and wildtype (Fig. 6b). As a result, the apoplastic invertase activity increased after
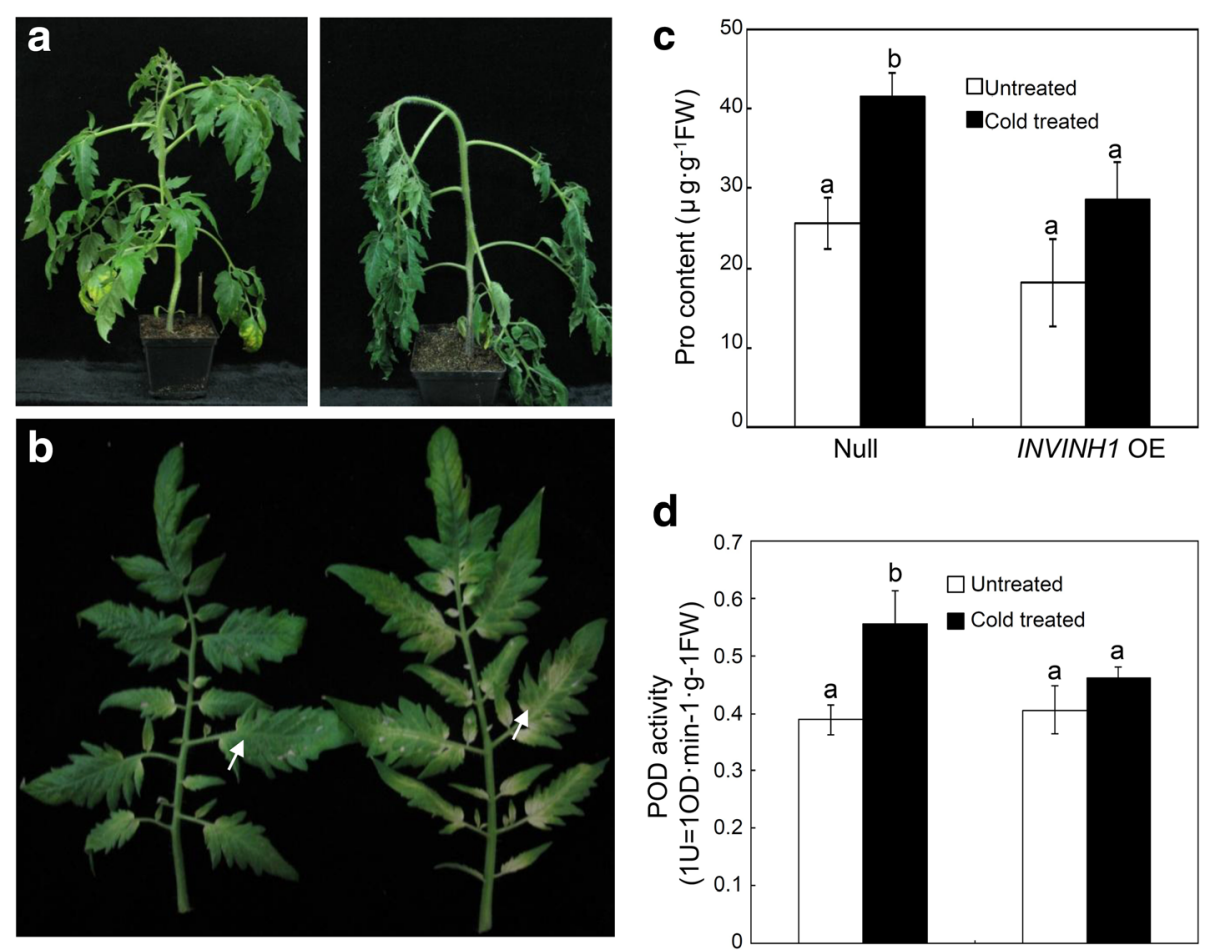

d

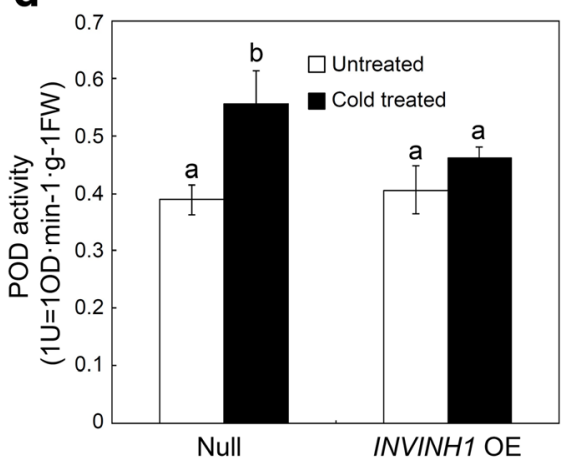

Fig. 5 Phenotypic responses of INVINH1 over-expression and wildtype under cold stress. a 45-d INVINH1 over-expression and wildtype plant were treated at $4{ }^{\circ} \mathrm{C}$ for $6 \mathrm{~h}$. The INVINH1 over-expression plant wilted, while wildtype plant remained normal. b The first mature leaf from 60-d INVINH1 RNAi and wildtype plant, which were recovered at $25^{\circ} \mathrm{C}$ for $72 \mathrm{~h}$ after treated at $4{ }^{\circ} \mathrm{C}$ for $24 \mathrm{~h}$. The leaf at this position of INVINHI over-expression plant turned white. By contrast, the leaf at the same position of wildtype remained green at this stage. $\mathbf{c}$ The proline content of the first mature leaf from INVINH1 over-expression and wildtype plant before and after treated at $4{ }^{\circ} \mathrm{C}$ for $24 \mathrm{~h}$. $\mathbf{d}$ The POD activity of the first mature leaf from INVINH1 over-expression and wildtype plant before and after treated at $4{ }^{\circ} \mathrm{C}$ for $24 \mathrm{~h}$. (POD activity: $1 \mathrm{U}=\mathrm{OD} \cdot \mathrm{min}^{-1} \cdot \mathrm{g}^{-1} \mathrm{FW}$ ). Each value in (c) and (d) is mean $\pm \mathrm{SE}$ of at least ten biological replicates. Lowercase letters indicate values significantly different at $P<0.05$ 

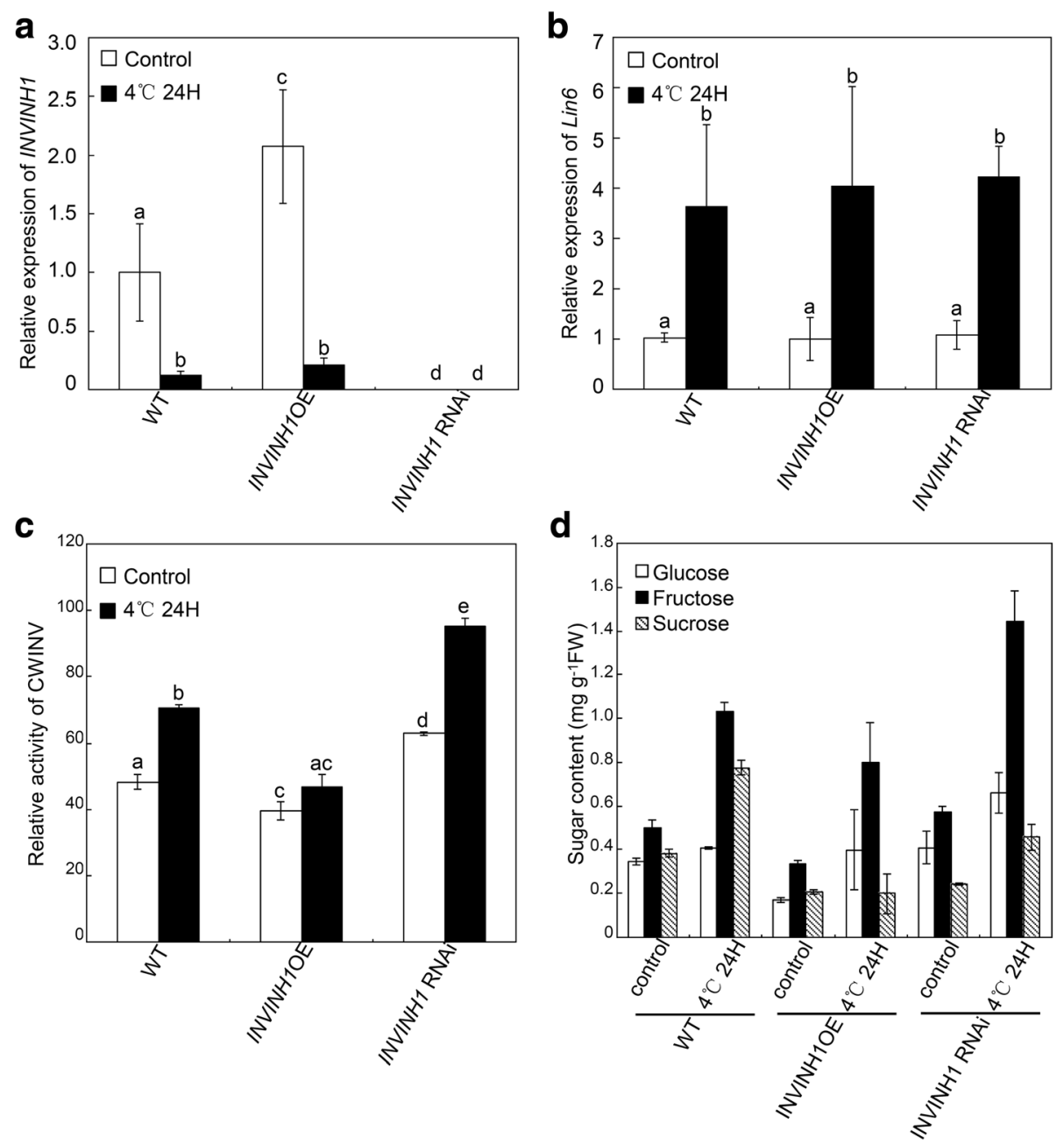

Fig. 6 The cell wall invertase activity and hexose content were induced by chilling stress and regulated by INVINH1. a Expression of INVINH1 in the first mature leaves of INVINHI over-expression, wildtype and RNAi plants before and after treated at $4{ }^{\circ} \mathrm{C}$ for $24 \mathrm{~h}$. Actin was used as the loading control. $\mathbf{b}$ Expression of cell wall invertase gene Lin6 in the first mature leaves of INVINH1 over-expression, wildtype and RNAi plants before and after treated at $4{ }^{\circ} \mathrm{C}$ for $24 \mathrm{~h}$. Actin was used as the loading control. c The activity of cell wall invertase in the first mature leaves of INVINH1 over-expression and RNAi plants before and after treated at $4{ }^{\circ} \mathrm{C}$ for $24 \mathrm{~h}$. $\mathbf{d}$ Sugar levels in the first mature leaves of INVINH1 over-expression, wildtype and RNAi plants before and after treated at $4{ }^{\circ} \mathrm{C}$ for $24 \mathrm{~h}$. Each value in (a), (b), (c) and (d) is mean \pm SE of at least four biological replicates. Lowercase letters indicate values significantly different at $\mathrm{P}<0.05$

treatment at $4^{\circ} \mathrm{C}$ for $24 \mathrm{~h}$ in both transgenic (INVINH1 overexpression and RNAi) and wildtype. Notably, although application of cold treatment increased the transcript levels of the cell wall invertase in INVINH1 overexpression plants, their apoplastic invertase activity was still lower than those in wildtype with or without cold treatment (Fig. 6c).

Sucrose increases in wildtype and INVINH1 RNAi under cold stress (Fig. 6d). Sugar measurement revealed increases in glucose and fructose levels after treatment at $4^{\circ} \mathrm{C}$ for $24 \mathrm{~h}$ in both transgenic (INVINH1 overexpression and silencing) and wildtype. The hexoses content increased when the expression of INVINH1 was silenced, before and after cold treatment. Consistently, the glucose and fructose levels decreased if the expression of
INVINH1 increased, before and after cold treatment (Fig. 6d).

\section{External glucose rescued the different phenotype caused} by the alteration expression of INVINH1 under chilling stress

The increase of sugar (glucose, fructose and sucrose) content by chilling stress, the increase or decrease in glucose and fructose content by silencing or overexpression of the cell wall invertase inhibitor INVINH1 and the resultant impact on cold tolerance in tomato indicated that tomato cold resistance is sensitive to sugar levels in vivo. If this is the case, exogenously applied sugars might have a positive impact on tomato cold tolerance. In consideration of glucoses not only act as 
sugars but also as signaling factor [47] and when external glucose supplied, the internal glucose, fructose and sucrose content accumulated in the same proportion [48], we hypothesized that exogenously applied glucose might contribute to chilling stress tolerance.

To test this hypothesis, we chose shoots at the same stage from the same position of the transgenic and wildtype plants and treated them at $4{ }^{\circ} \mathrm{C}$ for $24 \mathrm{~h}$ with applied $2 \%$ glucose or $2 \%$ mannitol in vitro. The results revealed that, similar to that observed above (Figs. 2 and 5), compared with the wildtype, the transgenic shoots overexpressing INVINH1 were sensitive to cold stress, and the transgenic shoots in which the expression of INVINH1 was silenced were relatively insensitive to chilling stress (Fig. 7a). However, when $2 \%$ glucose was added, these differences disappeared (Fig. 7b). These results suggested that the roles of INVINH1 in the cold tolerance response are overruled by high glucose level.

\section{Alteration of CBFs expression in INVINH1 overexpression and silenced plants under chilling stress}

To gain more insight into the role played by INVINH1 in the cold response, we monitored the expression of cold-responsive genes by real-time PCR analysis. CBFs are known to be involved in cold tolerance [49]. Cold induced the expression of CBFs in wildtype (Fig. 8a-c). We examined whether the expression levels of the CBFs were altered in the INVINH1 RNAi or overexpression plants. There was a significant reduction in transcript levels of $C B F 1, C B F 2$, and $C B F 3$ in the INVINH1 overexpression plants $2 \mathrm{~h}$ after $4^{\circ} \mathrm{C}$ treatment (Fig. 8a-C). The expressions of $C B F 1, C B F 2$, and $C B F 3$ were consistently increased in INVINH1 RNAi plants after treatment at $4^{\circ}$ $\mathrm{C}$ for $2 \mathrm{~h}$ (Fig. 8a-c). This suggests that INVINH1 affects cold stress tolerance by controlling CBFs transcription.

Glucose applied in vitro masked the differences in chilling tolerance of tomato caused by the different expressions of INVINH1 (see above) indicate that the transcription levels of $C B F s$ genes may be regulated by exogenously applied hexoses. To this end, we examined expression of $C B F s$ with or without $2 \%$ glucose in chilling tolerance, $2 \%$ mannitol was used as an osmotic control [50, 51]. Mannitol treatment did not affect the expression of CBFs (Fig. 8a-c and d-e). Figure 8d, e \& $\mathrm{f}$ showed that the transcripts of these three CBFs genes were significantly up-regulated after a 2-h chilling stress with $2 \%$ glucose or mannitol. However, no difference was detected in their mRNA levels between the transgenic plants and wildtype after exposure to $4^{\circ} \mathrm{C}$ for $2 \mathrm{~h}$ with $2 \%$ glucose. These results show that INVINH1 regulated the expression of CBFs gene by adjust the contents of glucose. Interestingly compared with mannitol, glucose only induced the expression of CBF3. These
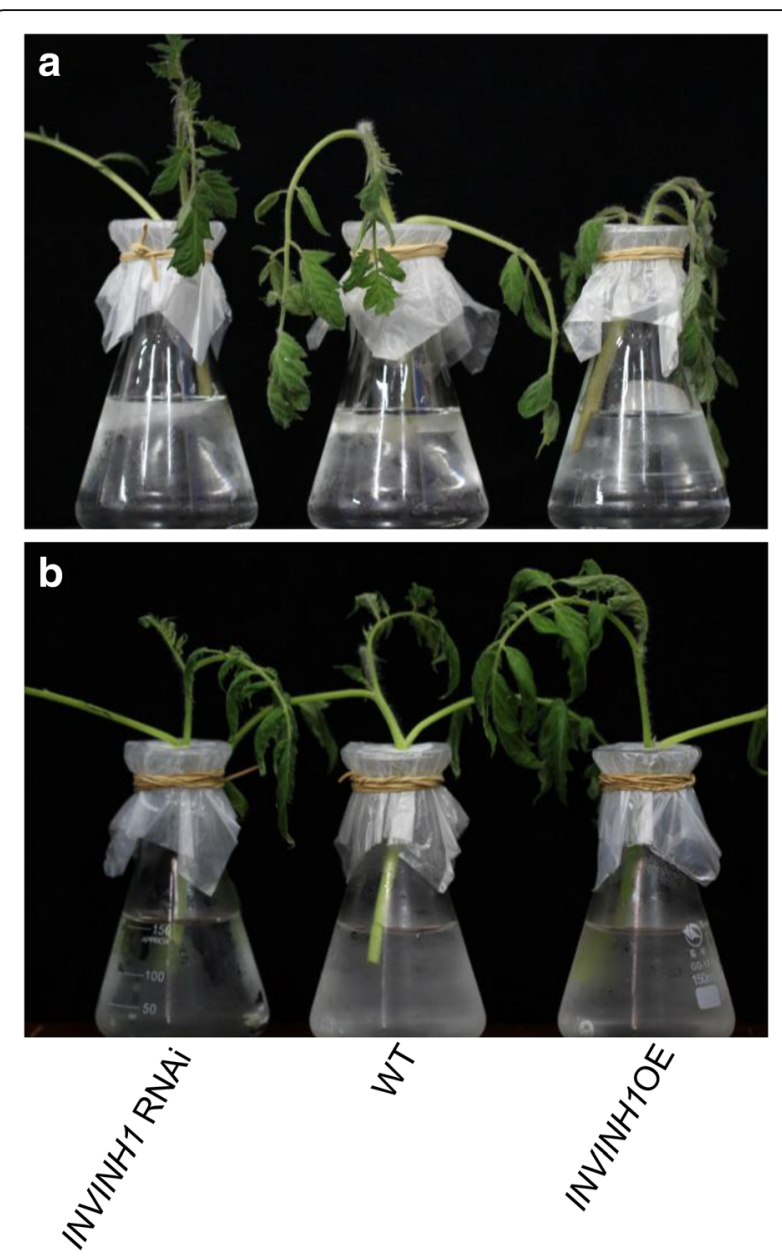

Fig. 7 Exogenous supply of glucose applied hided the differences of chilling tolerance in tomato shoots, which were caused by the different expression of INVINH1. a The shoots from the same position of 60-d INVINH1 RNAi, INVINH1 over expression and wildtype plant were immediately cut under water with $2 \%$ mannitol then treated at $4{ }^{\circ} \mathrm{C}$ of $24 \mathrm{~h}$. $\mathbf{b}$ The shoots from the same position of $60-\mathrm{d}$ INVINHI RNAi, INVINH1 over expression and wildtype plant were immediately cut under water with $2 \%$ glucose then treated at $4{ }^{\circ} \mathrm{C}$ of $24 \mathrm{~h}$

suggest that except by adjusting the contents of glucose, INVINH1 may have another inhibitory effect on cold tolerance.

INVINH1 suppressed endogenous ABA synthesis

$\mathrm{ABA}$ is an important signal in molecule plants' response to stresses, including cold, drought and salinity [52]. The application of ABA led to a strong increase of cell wall invertase inhibitor NtCIF mRNA in tobacco [23, 53]. ABA up-regulate the expression of cell wall invertase inhibitor INVINH1 and down-regulated the expression of cell wall invertase gene lin6 in tomato [18]. Notably, exogenous glucose specifically increased the expressions of ABA synthesis and signaling genes [54]. These observations 

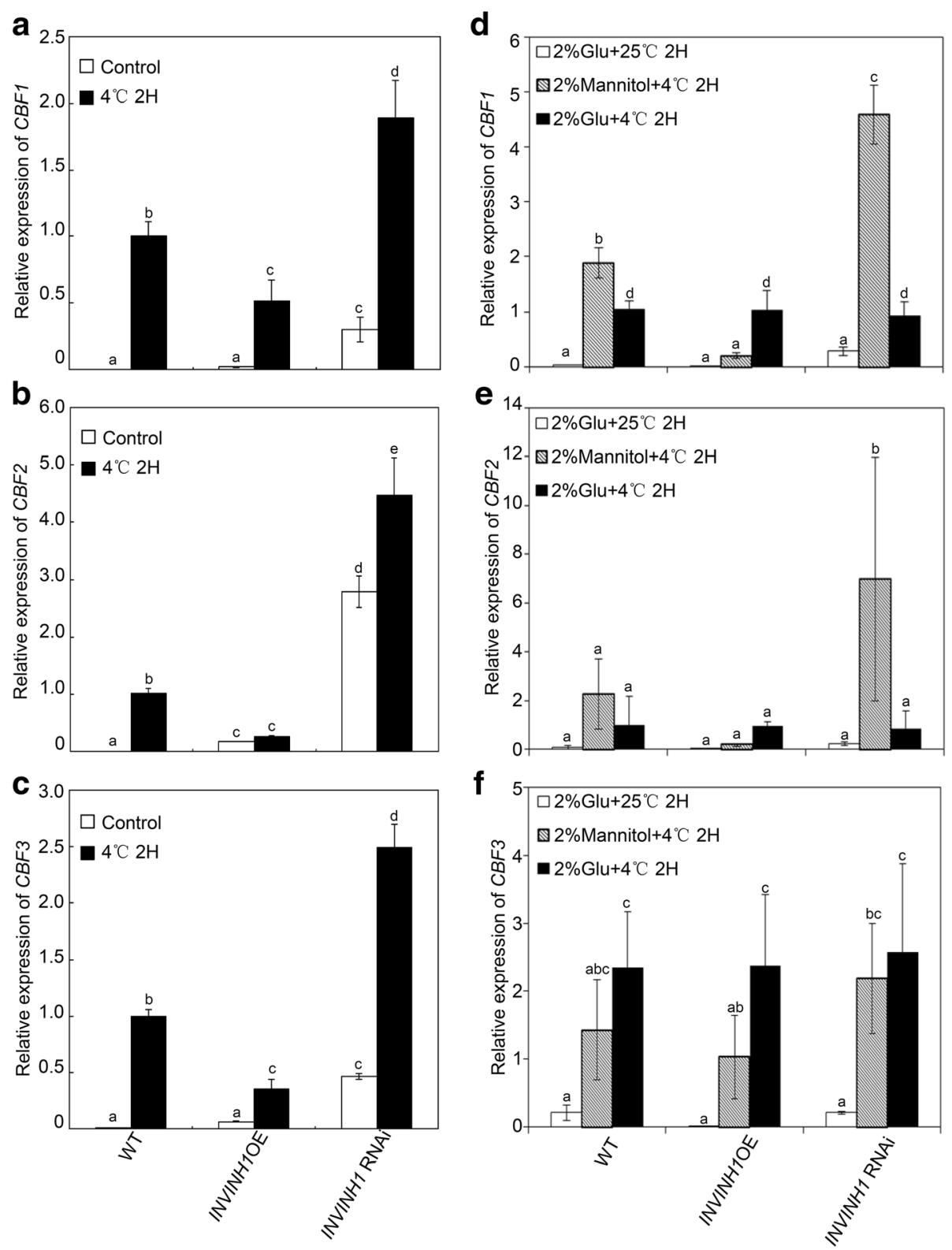

Fig. 8 Regulation of CBFs gene expression in wildtype, INVINH1 over-expression and RNAi plants. a CBF1 expression in wildtype, INVINH1 over-expression and RNAi plants before and after cold stress. The plants were stress-treated at $4^{\circ} \mathrm{C}$ for $2 \mathrm{~h}$. b CBF2 expression in wildtype, INVINH1 over-expression and RNAi plants before and after cold stress. The plants were stress-treated at $4{ }^{\circ} \mathrm{C}$ for $2 \mathrm{~h}$. c CBF3 expression in wildtype, INVINH1 over-expression and RNAi plants before and after cold stress. The plants were stress-treated at $4{ }^{\circ} \mathrm{C}$ for $2 \mathrm{~h}$. $\mathbf{d}$ qRT-PCR analysis of the expression profiles of CBF1 from the first mature leaf of in wildtype, INVINH1 over-expression and RNAi plants treated by $2 \%$ glucose or $2 \%$ glucose and chilling stress or $2 \%$ mannitol and chilling stress for $2 \mathrm{~h}$. e qRT-PCR analysis of the expression profiles of CBF2 from the first mature leaf of in wildtype, INVINH1 over-expression and RNAi plants treated by $2 \%$ glucose or $2 \%$ glucose and chilling stress or $2 \%$ mannitol and chilling stress for $2 \mathrm{~h}$. $\mathbf{f}$ qRT-PCR analysis of the expression profiles of CBF3 from the first mature leaf of in wildtype, INVINH1 over-expression and RNAi plants treated by $2 \%$ glucose or $2 \%$ glucose and chilling stress or $2 \%$ mannitol and chilling stress for $2 \mathrm{~h}$. Each value in $(\mathbf{a}),(\mathbf{b}),(\mathbf{c}),(\mathbf{d}),(\mathbf{e})$ and $(\mathbf{f})$ is mean \pm SE of at least four biological replicates. Actin was used as the loading control. Lowercase letters indicate values significantly different at $\mathrm{P}<0.05$

prompted us to examine whether INVINH1 affects cold stress tolerance by regulating ABA synthesis.

Environmental stress regulation of ABA biosynthesis primarily occurs at the transcriptional level [10]; therefore, we examined the expression of NCED1, which encodes 9-cisepoxycarotenoid dioxygenase (NCED), a key enzyme in the biosynthesis of ABA [55]. Quantitative RT-PCR analysis showed that before cold treatment, there was an increase in the expression levels of NCED1 in INVINH1 RNAi plants compared with wildtype (Fig. 
9a \& b). After cold treatment, NCED1 expression increased in both INVINH1 RNAi and wildtype plants; however, the expression levels of NCED1 in INVINH1 RNAi plants were still higher compared with wildtype (Fig. 9a). No significant differences in NCED1 expression were found between INVINH1 RNAi and wildtype plants after recovery at $25^{\circ} \mathrm{C}$ for $24 \mathrm{~h}$ after treatment at $4^{\circ} \mathrm{C}$ for $24 \mathrm{~h}$. Notably, in the INVINH1 overexpression plants, the expression of NCED1 was not obviously affected by low-temperature stress (Fig. 9a \& b). After $24 \mathrm{H}$ of cold treatment, the levels of endogenous ABA content of the first mature leaves from wildtype were significantly higher compared with INVINH1 overexpression plants and lower compared with INVINH1 RNAi plants (Fig. 9c). Furthermore Fig. 9d \& e showed that application of ABA protect plant from chilling damage caused by the different expression of INVINH1. These results suggested INVINH1 is probable involved in the regulation of endogenous ABA synthesis.

\section{Discussion}

Cell wall invertase inhibitor INVINH1 is involved in tomato chilling tolerance

Invertase inhibitor, which post-translationally regulates the activity of invertase, plays important roles in controlling fruit and seed development [18, 21, 28, 30, 31], leaves senescence [18], cold-induced sweetening of potato tubers $[12,29,22,33,56]$, fruit set under heat stress [57] and the plant defense response [58]. However, to the best of our knowledge, little evidence has been presented showing the involvement of the expression of cell wall invertase inhibitor or the activity of cell wall invertase in plant chilling tolerance.

Our results demonstrate that high cell wall invertase activities, which are regulated by cell wall invertase inhibitor (INVINH1), play important roles in chilling tolerance of tomato. First, cold treatment affected the transcript level of cell wall invertase and its inhibitor, and induced the activity of cell wall invertase (Figs. 1 \&
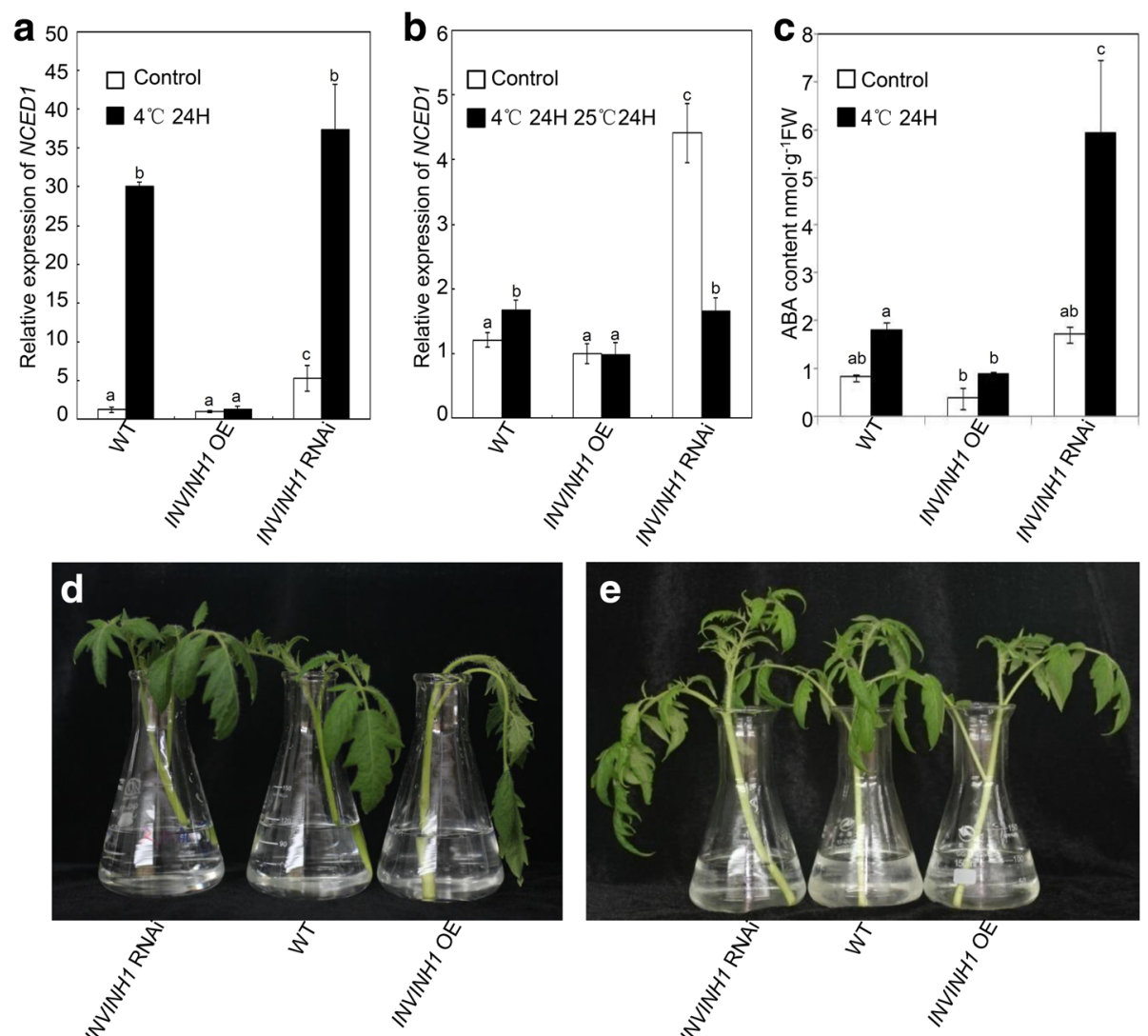

s
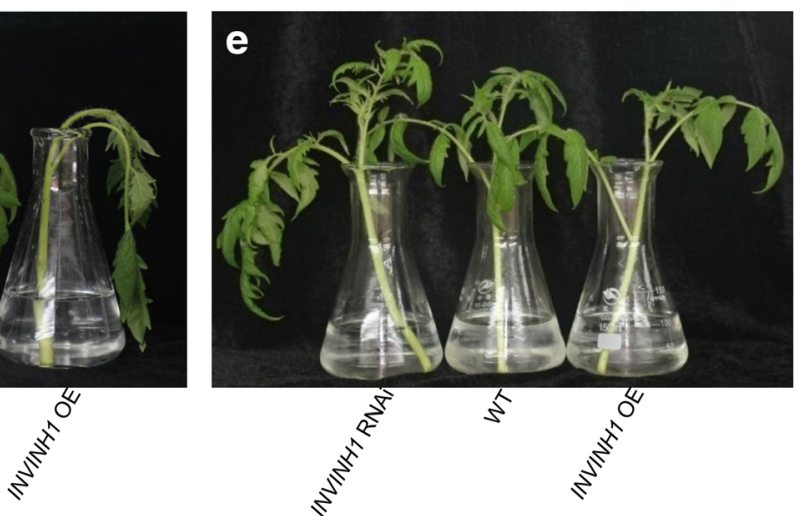

Fig. 9 Regulation of NCED1 gene expression in INVINH1 over-expression and RNAi plants. a NCED1 expression in INVINH1 over-expression and RNAi plants before and after treated at $4^{\circ} \mathrm{C}$ for $24 \mathrm{~h}$. Actin was used as the loading control. b NCED1 expression in INVINH1 over-expression and RNAi plants before and after cold stress. The plants were stress-treated at $4{ }^{\circ} \mathrm{C}$ for $24 \mathrm{~h}$ and then recovered at $25^{\circ} \mathrm{C}$ for $24 \mathrm{H}$. Actin was used as the loading control. c Endogenous ABA levels in the first mature leaves of INVINH1 over-expression, wildtype and RNAi plants before and after treated at $4{ }^{\circ} \mathrm{C}$ for $24 \mathrm{~h}$. $\mathbf{d}$ The shoots from the same position of 60-d INVINH1 RNAi, INVINH1 over expression and wildtype plant were immediately cut under water then treated at $4^{\circ} \mathrm{C}$ of $24 \mathrm{~h}$. e The shoots from the same position of 60-d INVINH1 RNAi, INVINH1 over expression and wildtype plant were immediately cut under water with $10 \mu \mathrm{M} \mathrm{ABA}$ then treated at $4^{\circ} \mathrm{C}$ of $24 \mathrm{~h}$. Each value in (a), (b) and (c) is mean \pm SE of at least four biological replicates. Lowercase letters indicate values significantly different at $P<0.05$ 
6). We hypothesized that repression of INVINH1 may be required for chilling tolerance. Second, the transformation of tomato with INVINH1 RNAi constructs led to enhanced chilling tolerance of the transgenic tomatoes (Fig. 2). These data demonstrated that the presence of the INVINH1 RNAi transgene is the causal basis of the observed enhanced chilling tolerance phenotype. By contrast, overexpression of INVINH1 in tomatoes made them more sensitive to cold stress compared with the wildtype plants (Fig. 5).These data confirmed the role of INVINH1 in tomato cold tolerance. Finally and importantly, the degree of INVINH1 expression correlated well with the level of plant chilling tolerance (Figs. 6 \& 7a). These results demonstrate that the tomato chilling tolerance is highly sensitive to changes in INVINH1 expression.

\section{INVINH1 regulated chilling tolerance by adjusting the expression of $C B F s$ genes and $A B A$ synthesis}

During cold tolerance, plants reprogram their gene expression through transcriptional, posttranscriptional and posttranslational mechanisms [59]. Among various factors, the CBF-dependent transcriptional pathway induces or is involved in cold tolerance in plants such as Arabidopsis [60], rice [61], wheat [62] and tomato [42]. In tomatoes, overexpression of Arabidopsis CBF1 gene increased chilling tolerance [42]. The underlying molecular mechanism, however, remains unclear. The expressions of CBFs were suppressed by INVINH1 after $4^{\circ} \mathrm{C}$ treatments (Fig. 8); therefore, we hypothesized that the repression of INVINH1 may be required for the CBF-dependent cold tolerance pathway. Silencing the expression of INVINH1 induced the expression of CBF genes, even before cold treatment (Fig. 8), indicating that the expression of INVINH1 is a prerequisite for CBF-dependent cold tolerance.

$\mathrm{ABA}$ accumulates during cold stress and is involved in chilling tolerance [52]. Our analyses revealed that the expression of INVINH1 affected the transcript level of the ABA synthesis gene NCED1 (Fig. 9). The above analyses concur with previous findings [10] that environmental stress regulation of ABA biosynthesis primarily occurs at the level of transcription; however, the expression of INVINH1 suppressed the expression of endogenous ABA synthesis (Fig. 9).

\section{INVINH1 controls cell wall invertase activity, which contributes to chilling tolerance by regulating the hexose content}

The glucose and fructose levels were induced after cold treatment in both wildtype and transgenic plants (Fig. 6d). These data suggested that the glucose and fructose contents need to reach optimum levels to protect the plant from the cold stress. This may be achieved by adjusting the activity of cell wall invertase, because the expression of a cell wall invertase gene (Lin6) was induced (Fig. 6b) and the cell wall inhibitor gene was depressed by cold treatment (Fig. 6a).

Cell wall invertase, whose activity is tightly regulated by its inhibitor in planta at the protein level, maintains the apoplastic glucose and fructose content at an optimum level [6]. Apoplastic glucose and fructose not only provide carbon nutrients, but also play major roles in sugar signaling. For example, in maize, mutation of a cell wall invertase (INCW2) resulted in a miniature seed phenotype [20,63].In tobacco, silencing the expression of cell wall invertase led to pollen abortion [64]. Interestingly, the phenotypes above, which were caused by cell wall invertase deficiency, could be partially, but not completely, recovered by exogenous supply of hexoses $[23,65]$. However, unlike the phenotype caused by cell wall invertase deficiency in reproductive tissue with rapid mitosis, in our study, the differences in chilling tolerance of tomatoes that were caused by different expressions of INVINH1 were totally blocked by the application of $2 \%$ glucose in vitro (Fig. 7).

\section{Conclusions}

Cell wall invertase inhibitor INVINH1 plays an important role in regulation of chilling tolerance in tomato by adjusting the sugar content, the expression of CBFs genes.

\section{Additional files}

\begin{abstract}
Additional file 1: Table S1. Primer sequences used for reverse transcriptase (RT)-PCR analysis of C-repeat binding factors (CBFs), ABA biosynthesis and signaling, and certain tomato invertase and invertase inhibitor genes. Figure S1. Phenotypic responses of INVINH1 RNAi line $2 \& 8$ and wildtype plant under cold stress. (A) Water loss rate of the leaves from The first mature leaf from 60-d INVINH1 RNAi and wildtype plant, which were recovered at $25^{\circ} \mathrm{C}$ for $2 \mathrm{~h}$ after treated at $4{ }^{\circ} \mathrm{C}$ for $48 \mathrm{~h}$. (B) The proline content of the first mature leaf from 60-d INVINH1 RNAi and wildtype plant before and after treated at $4{ }^{\circ} \mathrm{C}$ for $24 \mathrm{~h}$. (C) The POD activity of the first mature leaf from 60-d INVINH1 RNAi and wildtype plant before and after treated at $4{ }^{\circ} \mathrm{C}$ for $24 \mathrm{~h}$. (POD activity: $1 \mathrm{U}=\mathrm{OD} \cdot \mathrm{min}^{-1} \cdot \mathrm{g}$ ${ }^{-1} \mathrm{FW}$ ). Each value is mean $\pm \mathrm{SE}$ of at least ten biological replicates. Lowercase letters indicate values significantly different at $P<0.05$. Figure $\mathbf{S 2}$. Phenotypic responses of INVINH1 over-expression line 21 and wildtype plant under cold stress. (A) 65-d INVINH1 over-expression and wildtype plant were treated at $4{ }^{\circ} \mathrm{C}$ for $24 \mathrm{~h}$. The INVINHI over-expression plant wilted, while wildtype plant remained normal. (B) The first mature leaf from 65-d INVINH1 RNAi and wildtype plant, which were recovered at $25^{\circ} \mathrm{C}$ for $72 \mathrm{~h}$ after treated at $4{ }^{\circ} \mathrm{C}$ for $24 \mathrm{~h}$. The leaf at this position of INVINH1 over-expression plant turned white. By contrast, the leaf at the same position of wildtype plant remained green at this stage. (DOCX $731 \mathrm{~kb}$ )
\end{abstract}

\section{Abbreviations}

ABA: Abscisic acid; CBF: C-repeat binding factors; NCED1: 9cisepoxycarotenoid dioxygenase 1; OE: Overexpression; pl: Isoelectric point; POD: Peroxidase; RNAi: RNA interference; WT: Wildtype 


\section{Funding}

This work was supported by the National Natural Science Foundation of China (No. 31200192), the self-determined research funds of CCNU from the colleges' basic research and operation of MOE (No. CCNU11A0122), and the project of Hubei Key Laboratory of Genetic Regulation and Integrative Biology (No. GRIB201306). The funding bodies did not play a role in the design of the study and collection, analysis, and interpretation of data and in writing the manuscript, but just provide the financial support.

\section{Availability of data and materials}

The datasets used and/or analysed during the current study available from the corresponding author on reasonable request.

\section{Authors' contributions}

$W Y$ and $Y J$ designed research. $X X$ and $Y J$ carried out most of the experiments. QH performed quantitative RT-PCR. XX, QH, WY and YJ analyzed data. YJ wrote the paper. WY revised the manuscript. All authors have read and approved the final manuscript

\section{Ethics approval and consent to participate}

Tomato (Solanum lycopersicum XF-2) seeds "zhongshusihao" were purchased from the institute of vegetables and flowers Chinese academy of agricultural sciences. The tomato seeds have obtained the permission of Ministry of Agriculture of the People's Republic of China, which the phytosanitary certificate number is $130,922,006,820,110,062$

\section{Consent for publication}

Not applicable.

\section{Competing interests}

The authors declare that they have no competing interests

\section{Publisher's Note}

Springer Nature remains neutral with regard to jurisdictional claims in published maps and institutional affiliations.

\section{Received: 21 February 2017 Accepted: 31 October 2017}

\section{Published online: 09 November 2017}

\section{References}

1. Smeekens S, Rook F. Sugar-sensing and sugar-mediated signal transduction in plants. Plant Physiol. 1997;115:7-13.

2. Jang JC, Sheen J. Sugar sensing in higher plants. Plant Cell. 1994;6:1665-79.

3. Rolland F, Baena-Gonzalez E, Sheen J. Sugar sensing and signaling in plants: conserved and novel mechanisms. Annu Rev Plant Biol. 2006;57:675-709.

4. Schmolzer K, Gutmann A, Diricks M, Desmet T, Nidetzky B. Sucrose synthase: a unique glycosyltransferase for biocatalytic glycosylation process development. Biotechnology Advance. 2015:34:88-111.

5. Smeekens S. Sugar-induced signal transduction in plants. Annu Rev Plant Physiol Plant Mol Biol. 2000;51:49-81.

6. Ruan YL, Jin Y, Yang YJ, Li GJ, Boyer JS. Sugar input, metabolism, and signaling mediated by invertase: roles in development, yield potential, and response to drought and heat. Mol Plant. 2010;3:942-55.

7. Sturm A. Invertases: primary structures, functions and roles in plant development and sucrose partitioning. Plant Physiol. 1999;121:1-7.

8. Masuda H, Takahashi T, Sugawara S. The occurrence and properties of alkaline invertase in mature roots of sugar beets. Agric Biol Chem. 1987;51:2309-14.

9. Pelleschi S, Rocher JP, Prioul JL. Effect of water restriction on carbohydrate metabolism and photosynthesis in mature maize leaves. Plant Cell Environ. 1997;20:493-503.

10. Xiong L, Zhu JK. Regulation of abscisic acid biosynthesis. Plant Physiol. 2003; 133:29-36.

11. Klann EM, Hall B, Bennett AB. Antisense acid invertase (TIV1) gene alters soluble sugar composition and size in transgenic tomato fruit. Plant Physiol. 1996:112:1321-30

12. Greiner S, Rausch T, Sonnewald U, Herbers K. Ectopic expression of a tobacco invertase inhibitor homolog prevents cold-induced sweetening of potato tubers. Nat Biotechnol. 1999;17:708-11.

13. Wang L, Li XR, Lian H, Ni DA, He YK, Chen XY, Ruan YL. Evidence that high activity of vacuolar invertase is required for cotton fiber and Arabidopsis root elongation through osmotic dependent and independent pathways, respectively. Plant Physiol. 2010:154:744-56.

14. Sergeeva LI, Keurentjes JJ, Bentsink L, Vonk J, van der Plas LH, Koornneef M, Vreugdenhil D. Vacuolar invertase regulates elongation of Arabidopsis Thaliana roots as revealed by by QTL and mutant analysis. PNAS. 2006;103:29-99.

15. Dickinson CD, Altabella T, Chrispeels MJ. Slow-growth phenotype of transgenic tomato expressing ApoplasticInvertase. Plant Physiol. 1991;95:420-5.

16. Wang $L$, Ruan $Y L$. New insights into roles of cell wall invertase in early seed development revealed by comprehensive spatial and temporal expression patterns of GhCWIN1 in cotton. Plant Physiol. 2012;160:777-87.

17. Zanor MI, Osorio S, Nunes-Nesi A, Carrarib F, Lohse M, Usadel B, Kühn C, Bleiss W, Giavalisco P, Willmitzer L, Sulpice R, Zhou Y-H, Fernie AR. RNA interference of LIN5 in Solanum Lycopersicum confirms its role in controlling Brix content, uncovers the influence of sugars on the levels of fruit hormones and demonstrates the importance of sucrose cleavage for normal fruit development and fertility. Plant Physiol. 2009:150:1204-18.

18. Jin Y, Ni DA, Ruan YL. Posttranslational elevation of cell wall invertase activity by silencing its inhibitor in tomato delays leaf senescence and increases seed weight and fruit hexose level. Plant Cell. 2009;21:2072-89.

19. Wang E, Wang J, Zhu X, Hao W, Wang L, Li Q, Zhang L, He W, Lu B, Lin H, $\mathrm{Ma} \mathrm{H}$, Zhang G, He Z. Control of rice grain-filling and yield by a gene with a potential signature of domestication. Nat Genet. 2008:40:1370-4.

20. Cheng WH, Taliercio EW, Chourey PS. Sugars modulate an unusual mode of control of the cell-wall invertase gene (Incw1) through its 3' untranslated region in a cell suspension culture of maize. Proc Natl Acad Sci. 1999;96:10512-7.

21. Li Z, Palmer WM, Martin AP, Wang R, Rainsford F, Jin Y, Patrick JW, Yang $Y$, Ruan $Y$ L. High invertase activity in tomato reproductive organs correlates with enhanced sucrose import into, and heat tolerance of, young fruit. J Exp Bot. 2012;63:1155-66.

22. Lara MEB, Garcia MCG, Fatima T, Ehneß R, Lee TK, Proels R, Tanner W, Roitsch T. Extracellular Invertase is an essential component of Cytokininmediated delay of senescence. Plant Cell. 2004:16:1276-87.

23. Rausch T, Greiner S. Plant protein inhibitors of invertases. Biochimicaet Biophysica Acta. 1696;2004:253-61.

24. Hothorn M, Van den Ende W, Lammens W, Rybin V, Scheffzek K. Structural insights into the $\mathrm{pH}$-controlled targeting of plant cell-wall invertase by specific inhibitor protein. Proc Natl Acad Sci. 2010;107:17427-32.

25. Pressey R. Separation and properties of potato invertaseand invertase inhibitor. Arch Biochem Biophys. 1966;113:667-74.

26. Greiner S, Krausgrill S, Rausch T. Cloning of a tobacco apoplasmicinvertase inhibitor: proof of function of the recombinant protein and expression analysis during plant development. Plant Physiol. 1998;116:733-42.

27. Bate NJ, Niu X, Wang Y, Reimann KS, Helentjaris TG. Aninvertase inhibitor from maize localizes to the embryo surrounding region during early kernel development. Plant Physiol. 2004;134:246-54.

28. Qin G, Zhu Z, Wang WH, Cai JH, Chen Y, Li L, Tian SP. A tomato vacuolar Invertase inhibitor mediates sucrose metabolism and influences fruit ripening. Plant Physiol. 2016;172:1596-611

29. Liu X, Song B, Zhang $H_{1}$ Li XQ Xie C, Liu J. Cloning and molecular characterization of putative invertase inhibitor genes and their possible contributions to cold-induced sweetening of potato tubers. Mol Gen Genomics. 2010;284:147-59.

30. Tang XF, Su T, Han M, Wei L, Wang WW, Yu ZY, Xue YG, Wei HB, Du YJ, Greiner S, Rausch T, Liu LJ. Suppression of extracellular invertase inhibitor gene expression improves seed weight in soybean (Glycine max). J Exp Bot. 2017:68:469-82

31. Su T, Wolf $\mathrm{S}$, Han M, Zhao H, Wei H, Greiner S, Rausch T. Reassessment of an Arabidopsis cell wall invertase inhibitor AtCIF1 reveals its role in seed germination and early seedling growth. Plant Mol Biol. 2016:90:137-55.

32. Liu X, Lin Y, Liu J, Song B, Ou Y, Zhang H, Li M, Xie C. StInvInh2 as an inhibitor of StvacINV1 regulates the cold-induced sweetening of potato tubers by specifically capping vacuolar invertase activity. Plant Biotechnol J. 2013;11:640-7.

33. McKenzie MJ, Chen RK, Harris JC, Ashworth MJ, Brummell DA. Posttranslational regulation of acid invertase activity by vacuolar invertase inhibitor affects resistance to cold-induced sweetening of potato tubers. Plant Cell Environ. 2013;36:176-85.

34. Nakashima K, Yamaguchi-Shinozaki K. ABA signaling in stress-response and seed development. Plant Cell Rep. 2013;32:959-70. 
35. Hirayama T, Shinozaki K. Research on plant abiotic stress responses in the post-genome era: past, present and future. Plant J. 2010;61:1041-52.

36. Wingler A, Juvany M, Cuthbert C, Munné-Bosch S. Adaptation to altitude affects the senescence response to chilling in the perennial plant Arabisalpina. J Exp Bot. 2015;66:355-67.

37. Masclaux-Daubresse C, Purdy S, Lemaitre T, Pourtau N, Taconnat L, Renou J$P$, Wingler A. Genetic variation suggests interaction between cold acclimation and metabolic regulation of leaf senescence. Plant Physiol. 2007;143:434-46.

38. Wang LY, Meng X, Yang DY, Ma N, Wang GD, Meng QW. Overexpression of tomato GDP-L-galactose phosphorylase gene in tobacco improves tolerance to chilling stress. Plant Cell Rep. 2014;33:1441-51.

39. Ueda T, Pichersky E, Malik VS, Cashmore AR. Level of expression of the tomato rbcS-3A gene is modulated by a far upstream promoter element in a developmentally regulated manner. Plant Cell. 1989;1:217-27.

40. Darwesh RSS. Improving growth of date palm plantlets grown under salt stress with yeast and amino acids applications. Annals of Agricultural Sciences. 2013;58:247-56.

41. Bates LS, Waldren RP, Teare ID. Rapid determination of free proline for water stress studies. Plant Soil. 1973;39:205-7.

42. Hsieh TH, Lee JT, Yang PT, Chiu LH, Charng YY, Wang YC, Chan MT. Heterology expression of the Arabidopsis C-repeat/dehydration response element binding factor 1 gene confers elevated tolerance to chilling and oxidative stresses in transgenic tomato. Plant Physiol. 2002;129:1086-94.

43. Subramanian P, Kim K, Krishnamoorthy R, Mageswari A, Selvakumar G, Sa T. Cold stress tolerance in Psychrotolerant soil bacteria and their conferred chilling resistance in tomato (Solanum Lycopersicum mill.) under low temperatures. PLoS One. 2016;11:e0161592.

44. Yu L, Yan J, Yang YJ, He LZ, Zhu WM. Enhanced tolerance to chilling stress in tomato by Overexpression of a Mitogen-activated protein Kinase, SIMPK7. Plant Mol Biol Rep. 2016;34:76-88.

45. Singh S, Rathore M, GoyaryEmail D, Singh RK, Anandhan S, Sharma DK, Ahmed Z. Induced ectopic expression of at-CBF1 in marker-free transgenic tomatoes confers enhanced chilling tolerance. Plant Cell Rep. 2011;30:1019-28.

46. Ruan YL, Llewellyn DJ, Furbank RT. Suppression of sucrose synthase gene expression represses cotton fiber cell initiation, elongation, and seed development. Plant Cell. 2003;15:952-64.

47. Li L, Sheen J. Dynamic and diverse sugar signaling. Curr Opin Plant Biol. 2016;33:116-25.

48. Pourtau N, Marès M, Purdy S, Quentin N, Ruël A, Wingle A. Interactions of abscisic acid and sugar signalling in the regulation of leaf senescence. Planta. 2004;219:765-72.

49. Mboup M, Fischer I, Lainer H, Stephan W. Trans-species polymorphism and allele-specific expression in the CBF gene family of wild tomatoes. Mol Biol Evol. 2012;29:3641-52.

50. Cheng WH, Endo A, Zhou L, Penney J, Chen HC, Arroyo A, Leon P, Nambara E, Asami T, Seo M, Koshiba T, Sheen J. A unique short-chain Dehydrogenase/Reductase in Arabidopsis glucose signaling and Abscisic acid biosynthesis and functions. Plant Cell. 2002;14:2723-43.

51. Wang XQ, Zheng LL, Lin H, Yu F, Sun LH, Li LM. Grape hexokinases are involved in the expression regulation of sucrose synthase- and cell wall invertase-encoding genes by glucose and ABA. Plant Mol Biol. 2017; https:// doi.org/10.1007/s11103-017-0593-9.

52. Kim SY. Recent advances in ABA signaling. Journal of Plant Biology. 2007;50: $117-21$.

53. Sander A, Krausgrill S, Greiner S, Weil M, Rausch T. Sucrose protects cell wall invertase but not vacuolar invertase against proteinaceous inhibitors. FEBS Lett. 1996;385:171-5. QTL and mutant analysis. Proc. Natl. Acad. Sci. 2006, 103: 2994-99

54. Cho YH, Sheen J, and Yoo SD. Low glucose uncouples hexokinase1dependent sugar signaling from stress and defense hormone abscisic acid and $\mathrm{C} 2 \mathrm{H} 4$ responses in Arabidopsis. Plant Physiol. 2010;152:1180-2.

55. Sun L, Wang YP, Chen P, Ren J, Ji K, Li Q, Li P, Dai SJ, Leng P. Transcriptional regulation of SIPYL, SIPP2C, and SISnRK2 gene families encoding ABA signal core components during tomato fruit development and drought stress. J Exp Bot. 2011;62:5659-69.

56. Brummell DA, Chen RK, Harris JC, Zhang H, Hamiaux C, Kralicek AV, McKenzie MJ. Induction of vacuolar invertase inhibitor mRNA in potato tubers contributes to cold-induced sweetening resistance and includes spliced hybrid mRNA variants. J Exp Bot. 2011;62:3519-34.
57. Liu YH, Offler CE, Ruan YL. Cell Wall Invertase promotes fruit set under heat stress by suppressing ROS-independent cell death. Plant Physiol. 2016;172:163-80.

58. Bonfig KB, Gabler A, Simon UK, Luschin-Ebengreuth N, Hatz M, Berger S, Muhammad N, Zeier J, Sinha AK, Roitsch T. Post-translational derepression of invertase activity in source leaves via down-regulation of invertase inhibitor expression is part of the plant defense response. Mol Plant. 2010;3:1037-48

59. Chinnusamy $V$, Zhu J-K, Sunkar R. Gene regulation during cold stress acclimation in plants. Methods Mol Biol. 2010;639:39-55.

60. Dubouzet JG, Sakuma Y, Ito Y, Kasuga M, Dubouzet EG, Miura S, Seki M, Shinozaki K, Yamaguchi-Shinozaki K: OsDREB genes in rice, Oryza Sativa L., encode transcription activators that function in drought-, high-salt- and cold-responsive gene expression. Plant J 2003, 33: 751-763.

61. Ito Y, Katsura K, Maruyama K, Taji T, Kobayashi M, Seki M, Shinozaki K, Yamaguchi-Shinozaki K. Functional analysis of rice DREB1/CBF-type transcription factors involved in cold-responsive gene expression in transgenic rice. Plant Cell Physiol. 2006;47:141-53.

62. Pellegrineschi A, Reynolds M, Pacheco M, Brito RM, Almeraya R, YamaguchiShinozaki K, Hoisington D. Stress-induced expression in wheat of the Arabidopsis Thaliana DREB1A gene delays water stress symptoms under greenhouse conditions. Genome. 2004;47:493-500.

63. Miller ME, Chourey PS. The maize invertase-deficient miniature-1 seed mutation is associated with aberrant pedicel and endosperm development. Plant Cell. 1992:33:297-305.

64. Roitsch T, Balibrea ME, Hofmann M, Proels R, Sinha AK. Extracellular invertase: key metabolic enzyme and PR protein. J Exp Bot. 2003;54:513-24.

65. Roitsch T, González MC. Function and regulation of plant invertases: sweet sensations. Trends Plant Sci. 2004;9:606-13.

\section{Submit your next manuscript to BioMed Central and we will help you at every step:}

- We accept pre-submission inquiries

- Our selector tool helps you to find the most relevant journal

- We provide round the clock customer support

- Convenient online submission

- Thorough peer review

- Inclusion in PubMed and all major indexing services

- Maximum visibility for your research

Submit your manuscript at www.biomedcentral.com/submit
Biomed Central 